\title{
Mundos mediterráneos: el reino de Mallorca y el sultanato mameluco (siglos XIII-XV)
}

\author{
Pau Cateura Bennasser
}

\section{RESUMEN}

En el artículo se analizan las especiales características de las relaciones del reino de Mallorca medieval con los paises musulmanes, especialmente con Egipto. El desarrollo de las Cruzadas convierte a Egipto en pieza estratégica de primer orden, con un programa deliberado de aislamiento comercial, cuya intensidad fue deudora de la coyuntura política. Pese a las importantes limitaciones establecidas, existieron contactos comerciales frecuentes con Egipto, desde 1247, y con las plazas conectadas, como Chipre y Rodas.

Aunque el Magreb fue el área prioritaria de los intereses comerciales de los mercaderes isleños, Egipto ejerció un significativo atractivo por su oferta de productos como las especies y el algodón de alto valor.

\section{ABSTRACT}

The article analyses the special characteristics of the relationships of de Medieval Kingdom of Majorca with the Moslem countries, in particular with Egypt. The developement of the crusades made Egypt a leading strategic point, with a deliberate programme of commercial isolation, the intensity of which was due to the political situation. In spite of the important limitations established, there existed frequent commercial contact with Egypt, from 1247, and with connected places, such as Cyprus and Rhodes. Although the Maghreb was the main area of commercial interest of the island merchants, Egypt held a significant attraction because of its offer of highvalue products such as spices and cotton. 


\section{INTRODUCCIÓN}

En 1229 Jaime I, rey de Aragón, organizaba una flota para conquistar las islas Baleares. La flota partió a finales de agosto y logró conquistar la Medina Mayurqa musulmana, almohade, el 31 de diciembre de este mismo año. El resto de la isla y Menorca e lbiza no pasaron a control directo cristiano hasta 1287, cuando Menorca fue ocupada por Alfonso III de Aragón 1.

La conquista de las Baleares por los reyes de Aragón nos pone en evidencia un modelo peculiar de expansión, el de conquista y colonización, modelo después extendido, con singulares adaptaciones, a Sicilia (1282) y Cerdeña (1323). También la operación de Mallorca desentraña un elemento fundamental de la presencia catalano-aragonesa en el Mediierráneo, su capacidad militar, desarrollada durante siglos de conflictos con los musulmanes de la Península Ibérica.

Establecer las relaciones entre el reino de Mallorca y el sultanato de Egipto puede parecer excesivo, por la desigualdad política, demográfica y económica de ambas entidades. Egipto integra un reino soberano que, desde 1250, organiza y controla todo el territorio del Oriente próximo, el reino de Mallorca es una entidad política menor que entre el siglo XIII-XV depende de los reyes de la Corona de Aragón, aunque gozará de independencia política, con reyes propios, entre 1276 y $1343^{2}$.

Egipto es un potente mercado con abundancia y diversidad de oferta de productos propios y ajenos. El reino de Mallorca dispone de un sector agrario, que registra excedentes, muy limitado. La sal de Ibiza, tejidos de mediana calidad, aceite y vino de Mallorca, lana de Menorca. Pero hay algo en las islas que les favorece: Su situación geográfica. La ciudad musulmana de Argel está más cerca de Mallorca $(300 \mathrm{~km}$.) que Marsella $(480 \mathrm{Km}$.). La isla de Ibiza está más cerca de Argel que de Barcelona. El reino de Mallorca ofrece, por consiguiente, una posición geográfica privilegiada frente a grandes mercados cristianos y musulmanes. La apertura del estrecho de Gibraltar no dejará de favorecer la posición de las Baleares, como ruta de paso de las flotas veneciana y genovesa.

\footnotetext{
1 La operación de conquista de las Baleares aparece relatada por el mismo Jaime I en el llamado Llibre dels Feits (Barcelona, Editorial Selecta, 1971, pp. 26-62). Entre 1229-1232 sólo se conquistó Mallorca y se sometió a vasallaje a Menorca. Ibiza se mantuvo como territorio musulmán independiente hasta 1235.

2 La llamada dinastía independiente de Mallorca estuvo integrada pro Jaime II (1276-1311), Sancho (1311-1324) y Jaime III (1324-1329 minoría de edad bajo tutela del infante Felipe, 13301343 mayoría de edad).
} 
Las caravanas de Mallorca son sus barcos. Pronto los insulares se unirán a las expediciones genovesas por el Atlántico Norte y Atlántico Sur, y recorrerán el Mediterráneo como mercaderes, como contrabandistas, como corsarios, como predicadores (Ramón Llull en Túnez) y conversos al Islam (Anselmo Turmeda, al servicio del sultán de Túnez a fines del siglo XIV) ${ }^{3}$. Es cierto que castellanos y catalano-aragoneses pactarán, en 1291, una división de las repectivas áreas de influencia en el Norte de Africa: Marruecos para Castilla y el resto para la Corona de Aragón. Pero estas delimitaciones no empecen la presencia mallorquina en Marruecos y la castellana en el Mediterráneo más allá de las divisorias establecidas.

Egipto y Baleares, colocados a ambos extremos del Mediterráneo, comparten un mar caracterizado por la cultura, milenaria en el caso de Egipto, por el intercambio mercantil y por la fascinación, iniciada ya por los más viejos habitantes de Baleares que en el segundo milenio antes de Cristo adquirieron una estatuilla de Imhotep (visir de la III dinastía), hoy expuesta en Mallorca como una pieza insigne. Dicha fascinación se mantendrá íntegra en la Edad Media. Los sultanes de Egipto recibirán en el área catalano-aragonesa el nombre, un tanto bíblico, de sultanes de Babilonia.

\section{EL CONTEXTO MEDITERRÁNEO DE LOS S. XIII-XV}

El siglo xIII es un período de crecimiento, de conflictos y también de oportunidades. Como balance global parece como si el mundo islámico se expandiera por el Mediterráneo Oriental, mientras entrará en declive en el Mediterráneo Occidental. Los almohades, ordenadores del Magreb y de la Península Ibérica entran en decadencia en la década de 1230-1240. El espacio político que habían sido capaces de crear quedó pulverizado en entidades independientes como el reino de Granada, en la Península Ibérica, y los sultanatos magrebíes de Fez, Tremecén (con Honein, Argel y Tenes) y Túnez (con Bugía, Bona, Alcoll, Túnez y Constantina).

En el Mediterráneo Oriental la remodelación parece incluso más profunda. La $4{ }^{a}$ Cruzada provoca el desmantelamiento del Imperio Bizantino de acuerdo con los intereses venecianos y la reordenación de Oriente Próximo primero por la dinastía Ayyubida (1171-1250) y después por la di-

3 Sobre el comercio exterior de las islas Baleares en los siglos XIII-XIV, D. ABULAFIA: Un emprorio mediterráneo. El reino catalán de Mallorca, Barcelona, Ediciones Omega, 1996. 
nastía turca de los Mamelucos (1250-1517) ${ }^{4}$. El resultado fue evidente. Si Saladino había conquistado Jerusalén en 1187, el sultán de Egipto Ahsraf Salah ad- Din Khalil conquistará San Juan de Acre, en 1291, el último enclave de los reinos cruzados. Pocos años antes, la victoria de Homs había conjurado el expansionismo de los mogoles ${ }^{5}$.

El dominio de Siria y Palestina convierte a los sultanes de Egipto en interlocutores necesarios para negociar cualquier solución respecto ya no de Jerusalén sino de los Santos Lugares. La mencionada 4. ${ }^{\text {a }}$ Cruzada pareció entenderlo así al tener el proyecto inicial de dirigirse a Egipto y después Luis IX de Francia también insistió, en 1248-1250, en destruir Egipto para liberar Jerusalén, con resultados catastróficos ${ }^{6}$. Quizás, en algunos casos la fe mueve montañas, pero no asegura el éxito de los ejércitos.

En cualquier caso, desde la toma de Jerusalén por Saladino el Papado genera una política altamente restrictiva en las relaciones comerciales de los cristianos con los dominios del sultán de Egipto. A las prohibiciones genéricas de épocas anteriores de vender armas, madera y materiales de construcción de naves se añaden, durante el siglo XIII, otras mercancías hasta el límite de 1290 en que a las prohibiciones habituales se añade "y cualquier otra mercadería».

Es tal el deseo de limitar los intercambios que llega un momento en que los municipios reclaman normativas en positivo, es decir, qué mercancías no prohibidas pueden llevar a Egipto. A una consulta de los venecianos, el Papa Benedicto XI permitió la exportación de tejidos y trajes, todo ello con independencia del dinero en efectivo.

El control de los mercados mediterráneos por los reinos y entidades cristianas también cambió de forma significativa. La mencionada 4. ${ }^{a}$ Cruzada desalojó a los genoveses, en favor de los venecianos, de la posición preeminente en el imperio Bizantino, pero el conflicto entre Pisa y Génova se resolvió en 1284 (batalla de Melória) a favor de los genoveses y éstos recuperan posiciones en Bizancio desde fines del siglo XIII. El conflicto entre los reyes de Aragón y de Francia se resolvió a favor de los segundos en una primera etapa (entrada de Provenza en la órbita francesa,

4 C. E. Bosworth: Les dynasties musulmanes, Dijon, Editorial Sindbad, 1996, pp. 95- 104. Su autor afirma que les Mamluks s'acquirent un inmense prestige dans le monde islamique tout entier, en tant que pourfendeuurs des Mongols et des chrétiens.

5 A. Masía de Ros: La Corona de Aragón y los Estados del Norte de Africa, Barcelona, Instituto Español de Estudios Mediterráneos, 1951, pp. 19-133.

6 Croisades et pèlerinages. Récits, chroniques et voyages en Terre Sainte (XII-XVI siècle), (Edition de Danielle Regnier-Bohler) Paris, Robert Laffont, 1997. 
tratado de Corbeil y Carlos d'Anjou, rey de Nápoles y Sicilia a partir de 1266), pero a finales del siglo se reequilibró la situación cuando los reyes de Aragón ocuparon Sicilia (1282) ${ }^{7}$.

El contencioso con Francia no fue un obstáculo para que la Corona de Aragón afirmara posiciones en el Norte de Africa, desde el establecimiento de un consulado en Alejandria, negociado en 1262, hasta las relaciones de protectorado sobre el sultanato de Túnez ${ }^{8}$.

La Corona de Aragón sale del siglo xIII como una potencia mediterránea. No es extraño que Jaime II (1291-1327) intentara extender más allá de Sicilia la influencia catalana al casarse con María de Lusignan, perteneciente a la familia reinante en Chipre. Esta isla había sido conquistada como alternativa a la pérdida de Sant Juan de Acre y poco después, en 1310, la Orden del Hospital ocupó a los bizantinos la isla de Rodas. Chipre, y Rodas se incorporan a una nueva ruta comercial en la que se integrará también Quíos, concedida por los bizantinos a los genoveses en $1304^{9}$.

Debemos resaltar estos datos por un doble motivo: por la conexión de dichas islas con el mundo egipcio y sirio, y porque Chipre y Rodas serán plazas comerciales frecuentadas por comerciantes mallorquines desde fechas tempranas. El mismo Egipto fue objeto de intensas prospecciones diplomáticas, al menos durante el período del mencionado Jaume II, constando seis embajadas durante su reinado.

Pero las relaciones con los dominios del sultán de Egipto estaban dominadas, a nivel oficial, por las prescripciones papales. Ya en 1274, Jaime I el Conquistador había tenido que reconocer la prohibición absoluta de comercio con Egipto. El conflicto de los reyes de Aragón con el Papado, por la conquista de Sicilia, determinó acercamientos estratégicos a Egipto, rápidamente anulados tras la firma del tratado de Anagni (1295). Después la política real actuó a un doble nivel: mantener oficialmente la prohibición de comerciar con Egipto y a la vez implantar un sistema de multas a los trans-

\footnotetext{
7 Sobre la Sicilia de fines dels siglo XIII interesa especialmente el «XI Congreso di Storia della Corona d'Aragona» dedicado a «La società mediterranea all'epoca del Vespro», Palermo, Academia di Scienze, Lettere e Arti», 1983, 4 volúmenes.

J. M. a Madurell y A. García Sanz: Comandas comerciales barcelonesas de la baja Edad Media, Barcelona, Anejos del «Anuario de Estudios Medievales», 1973. Más reciente y completa, M. ${ }^{a}$ D. López: La Corona de Aragón y el Magreb en el siglo XIV (1331-1410), Barcelona, Consejo Superior de Investigaciones Científicas, 1995.

9 F. Fernández-Armesto: Antes de Colón (1229-1492), Madrid, Ediciones Cátedra, 1993, pp. 116-135. También interesa, H. A. MiskimiN: La economía de Europa en el alto Renacimiento (13001460), Madrid, Ediciones Cátedra, 1980.
} 
gresores (10\% del valor de las mercancías). Inicialmente las multas eran ingresadas por el Papado, pero desde 1297 trasferidas al rey de Aragón con ciertas condiciones.

Durante el siglo XIV las relaciones comerciales de la Corona de Aragón con el Levante mediterráneo no siempre fueron fáciles. Los catalanes disponían de un consulado en Beirut, desde 1347, trasladado en 1379 a Damasco. Pero en 1365 se dejan arrastrar a una cruzada del rey de Chipre, Pedro I, contra Egipto. Alejandría fue saqueada, y el sultán ordenó represalias contra los mercaderes catalanes. Sólo cinco años después, en 1370, fue firmada la paz, reabriéndose al comercio cristiano el puerto de Alejandría. Nuevos incidentes en 1386, con la captura de cargamentos egipcios embarcados en naves tunecinas, obligaron a una suspensión temporal de relaciones.

Por otra parte la correlación de fuerzas entre las potencias mediterráneas cambió a lo largo del siglo indicado. Un largo conflicto mantiene Génova con la Corona de Aragón, bien directamente (1330-1336, 13511353) o indirectamente (sublevaciones de Cerdeña, conquistada por los aragoneses en 1323) ${ }^{10}$ y con Venecia (1351-1353 y la guerra de Chioggia de 1378-1381). En el Levante Mediterráneo se produce la desintegración del Imperio Bizantino, la ocupación por los turcos de gran parte de los Balcanes y la invasión de Siria por Tamerlán (saqueo de Damasco de 1401) y su lucha con Bayaceto (1402).

El siglo XV tuvo como consecuencia una remodelación definitiva de Oriente Próximo. Los turcos otomanos concluyen operaciones iniciadas en el siglo anterior con la ocupación de Constantinopla, pasando a controlar el Mar Negro. Las potencias comerciales tradicionales inician un repliegue. En 1416 Siria desaparece del comercio catalán. Los genoveses se repliegan de sus bases comerciales, manteniendo sólo Quíos. Los venecianos, los que tienen mayores intereses que defender, inician una guerra contra los turcos (1463-1476) con grandes perjuicios. Sólo Rodas y Chipre parecen mantenerse durante cierto tiempo, aunque la primera empezó a experimentar graves dificultades desde 1480 y la segunda estuvo bajo protectorado Egipcio durante cierto tiempo.

Egipto, durante el siglo $x v$, parece mantenerse fuera de los grandes conflictos. Durante largo tiempo los turcos otomanos se encuentran ocupados en operaciones europeas. Es una época de riqueza y de esplendor,

\footnotetext{
10 A la problemática de Cerdeña entre los siglos XII-XV estuvo dedicado el «XIV Congresso di Storia della Corona d'Aragona", Sassari, Carlo Delfino Editore, 1993, seis volúmenes.
} 
foco de atracción de los comerciantes catalanes y mallorquines. Pero ni la Corona de Aragón, ni Venecia, ni Génova, ni incluso Florencia eran una sombra de lo que habían sido en los siglos XIII y XIV. Durante la primera mitad del siglo $x \mathrm{~V}$, Alfonso $\mathrm{V}$ de Aragón potenció las relaciones con el sultanato mameluco. De esta época data un importante tratado comercial, firmado en Rodas en 1430, donde se instaura una avance cualitativo en la posición jurídica del consulado catalán de Alejandría. Se acepta el principio de extraterritorialidad del consulado ${ }^{11}$. Después, Cataluña queda sumida en una grave guerra civil (1462-1473), Génova intentó trasladar sus negocios al Mediterráneo Occidental y al Atlántico. Venecia se orientó hacia una economía industrial, aunque a fines del siglo xv logró ocupar Chipre ${ }^{12}$.

\section{EL TRÁFICO DEL REINO DE MALLORCA Y EL SULTANATO DE EGIPTO}

Las relaciones de Mallorca y Egipto en la Edad Media son tan antiguas como el año 1233, cuando el conde del Rosellón, Nuño Sanç, concedió unas casas en la capital de Mallorca a Barobe de Alejandría, hijo del judío Aaron. Pero lamentablemente, las relaciones con Egipto son la hermana pobre de la historiografía balear. Es interesante comprobar cómo en una reciente obra, su autor dedica solamente dos referencias a Egipto en todo el libro; la primera para relatar el viaje, en 1184, de Ibn Jubayr desde Ceuta a Alejandría, pasando por Denia y las Baleares. La segunda referencia es para señalar que también en invierno había un intenso tráfico tanto hacia Egipto como hacia el Atlántico. El puerto de Alejandría no recibe mejor tratamiento. Tan sólo menciona este autor el tráfico de conchas cauri (utilizadas como moneda en determinados lugares) y en la exportación a Alejandría de paños y aceite y la importación de especias ${ }^{13}$.

Evidentemente, el problema no es tanto del autor mencionado como de la tradicional focalización de la historiografía balear, incluso catalana,

11 M. VILADRICH: Jaque al sultán en el «damero maldito». Edición y traducción de una tratado diplomático entre los mercaderes catalanes y el sultanato mameluco, en “L'expansió catalana a la Mediterràmnia a la baixa Edat Mitjana», Barcelona, CSIC, 1999, pp. 160-205.

12 El rey Jacobo de Chipre se casó con la veneciana Catalina Cernaro. Catalina enviudó en 1473, pasando a ejercer la regencia en nombre de su hijo. Pero en 1489 se vio forzada por Venecia a cederle sus derechos.

13 D. Abulafia: Un emporio.., pp. 137, 138, 141, 145, 157 y 275. 
hacia el Mediterráneo Occidental, en una área en la que el Magreb, Cerdeña y Sicilia han sido el centro de la atención de los historiadores, desde la época de $\mathrm{CH}$. E. Dufourcq ${ }^{14}$ y Federico Melis ${ }^{15}$.

Todo lo anterior nos conduce a un tema pendiente de la historiografía balear. Por esta razón, lo que voy a presentar aquí es un esbozo, un cuadro general de las relaciones de Mallorca con Egipto a la luz de los datos publicados y de algunas investigaciones propias. Pero antes de examinar dichas relaciones quiero establecer algunas premisas del comercio exterior del reino de Mallorca:

a) Desde la misma fundación del reino de Mallorca y hasta mediados del siglo XIV los genoveses ocupan un papel preponderante en la organización y orientación del comercio exterior de Mallorca. Dicho papel quedó incluso realzado en la época de independencia del reino de Mallorca, cuando un hijo de genovés, Pere Bossa, llegó, en 1332, a la máxima magistratura de Jurado de Mallorca y de consejero y prestamista real ${ }^{16}$.

b) En los siglos XIII y XIV las barcas y leños componen el grueso de la flota comercial insular. No es extraño que el único documento estadístico de tráfico comercial del siglo XIII, datado en 1284, se denomine «Llicència per a barques» ${ }^{17}$ y que el rey Sancho, en 1320 , consciente de la irradiación del comercio exterior insular al Atlántico y al Levante mediterráneo, promueva la reconversión de la flota comercial sobre la base de las galeras. El objetivo real no se cumplió en el siglo XIV, donde la coca parece reinar entre los buques de alto bordo, pero sí en el siglo xv como veremos después.

c) La condición insular del reino y su necesaria revalorización económica generan, desde muy pronto, una documentación permisiva del tráfico con los musulmanes. Entre 1240 y 1248 se conservan tres bulas papales autorizando, con determinadas restricciones, el comercio de los mallorquines con los musulmanes:

14 L'expansió catalana a la Mediterrània occidental (segles XII-XI), Barcelona, Editorial Vicens Vives, 1969. Del mismo autor, Aspectes internationaux de Majorque durant les derniers siècles du Moyen Age, en «Mayurqa" 11 (1974), pp. 5-52.

15 L'area catalano-aragonese nel sistema economico del Mediterraneo occidentale, en "IX Congreso de Historia de la Corona de Aragón», Nápoles, 1978, pp. 191-209.

16 P. Cateura Bennasser: El regne esvaït (desenvolupament económic, subordinació política, expansió fiscal, 1300-1335), Palma, Editorial El Tall, 1998, p. 53. La presencia de una Jurado de origen genovés fue objeto de crítica por ciertos sectores. El mercader catalán Bernat Socarrats, en 1333, acusaba al municipio de que ipsa civitas nullatenus poterat bene regi dum fili januensium inimicorum nationis et dicti civitatis esset jurati.

17 Publicado por A. RIERA MELIS: La "Licència per a barques" de 1284, una font important per a l'estudi del comerç exterior mallorqui del darrer quart del segle XH, Palma de Mallorca, Fontes Rerum Balearium, Volumen III, 1979-1980, pp. 121-140. 
- El 28 de enero de 1240, Gregorio IX, permitía el comercio de vituallas con los musulmanes en épocas de paz, preter equos et mulos, arma, ferrum et lignamina; victualia tempore pacis ferre possint et vendere ${ }^{18}$.

- Un año después el mismo Papa reiteraba la licencia de comercio anterior, exceptis armis, ferro et aliis quibus possit populus christianus impugnari sarracenis in remotis partibus habitantibus, en clara alusión al Levante mediterráno, especialmente Egipto.

- Finalmente, en 1248, Inocencio IV autorizaba de nuevo el comercio de vituallas, en tiempos de paz, con los musulmanes, excepto equos et mulos, arma, ferrum et lignamina.

Las mencionadas bulas tuvieron efectos inmediatos que, a pesar de la deficiente documentación conservada de la época, pueden contrastarse. En el cuadro siguiente establezco los trayectos, tipos de embarcaciones y patrones de los años 1240-1241:

Tráfico exterior de Mallorca (1240-1241)

\begin{tabular}{lll}
\hline \multicolumn{1}{c}{ Trayecto } & Tipo embarcación & \multicolumn{1}{c}{ Patrón } \\
\hline 1240: Hispania-Sabut & - & J. Ferrán \\
Denia-Valencia & barca & B. Ferrán \\
Hispania & barca & A. de Tamarít \\
Bona & leño & Berenguer de Villa de Caules \\
Hispania & leño & Ramon Moyà \\
Hispania & barca & A. Calafat y P. Ricart \\
Túnez y Sabut & navis et galea & Berenguer de Montcada \\
Argel & leño & Guillem de Bona \\
Barcelona & leño & Bernat Ferré \\
Montpellier & barca c leño & Jaspert de Sant Feliu \\
1241: Hispania & barca & J. Ferrán \\
Túnez & - & R. Boter \\
Hispania & barca & J. Ferrán \\
Sabud & barca & B. Safont \\
Hispania & barca & B. de Claver(?) y Bernat F. \\
Túnez-Sabut & navis et galea & Bernat Annunci \\
Hispania & barca & Robert de Tarragona \\
\hline
\end{tabular}

18 L. PÉrez y B. Coll: Ramon de Torrelles, primer bisbe de Mallorca, Palma de Mallorca, Col’lecció La Seu, 1988, pp. 25-87. 
La tabla anterior no es estadística porque la documentación de la época no lo permite ${ }^{19}$, pero es significativa de la rapidez con que los mallorquines hacen uso de las bulas papales. Por otra parte resulta significativo que ya uno de los viajes de 1240 es no sólo una empresa comercial sino también una misión oficial, embarcándose un nuncius domini regis ${ }^{20}$.

Ya uno de los viajes de 1240, el de Guillem de Bona, señalaba que su destino era Argel u otro puerto indeterminado de la región, sin especificarlo. Después la documentación relaciona algunas travesías a Ultramar:

- En 1247 el patrón de nave Bernat Blanc había realizado una travesía hasta Alejandría.

- En 1252, los patrones genoveses de nave Lafranco Rosso de Orto y Simón de Lavanto reconocían que el agente mallorquín Bernat Piquer les había prestado 3200 sueldos, para el pago de la marinería, en una travesía de ultramarinis partibus hasta Mallorca.

- En 1256 el mercader mallorquín Bernat Porter fletó la nave del patrón barcelonés Ferrán Ausell para un viaje a Alejandría. En la nave se embarcaron comandas en dinero (990 besantes alejandrinos y 73 libras y 19 sueldos) y en mercancías (vino, aceite, miel y tejidos). En las operaciones de comanda participaron no sólo mercaderes mallorquines sino también barceloneses, marselleses, aragoneses y genoveses. Era una travesía comercial pero también oficial, ya que dicho Bernat Porter figuraba como emisario del rey cerca del sultán de Egipto ${ }^{21}$.

- En 1260, el mercader y banquero de Mallorca Joan Homdedeu recibía 14.880 sueldos, en efectivo, de dos mercaderes de Barcelona para negociarlos en Alejandría ${ }^{22}$. No parece que las ganancias obtenidas por Joan Homdedeu fueran modestas, ya que siete años después arrendó a Jaime I todas las rentas y derechos reales de Mallorca, valorados en 45.000 sueldos ${ }^{23}$.

19 Archivo del Reino de Mallorca, ECR 341, fols. 119 r., 119 v., 120 v., 121 r., 122 v., 130 v., 131 r.; ECR 342, fol. 9 v.; ECR 343, fols. 272 v. y 274 v. Estos primeros registros de documentos aparecen totalmente desorganizados.

20 El capitán de la navis et galea era Berenguer de Montcada que el 29 de diciembre de 1240 figura embarcando 125 cuarteras de cebada (medida de áridos equivalente a 8750 litros) para Túnez y Sabut.

21 A. Santamaría: Don Pedro, infante de Portugal, señor del reino de Mallorca (1231-1256), Palma de Mallorca, 1975, p. 29.

22 J. M. Madurell y A. García Sanz: Opus cit, pp. 160-161.

23 P. Cateura: Mallorca a la segona meitat del segle XIII (aspectes politics i financers fins a 1276) en «Estudis Baleàrics» 17 (Palma de Mallorca, 1985), pp. 77-79. 
La actividad mallorquina en el Levante mediterráno parece disminuir a partir de 1270 y en la década siguiente cesar de forma más o menos completa. En el contexto de la guerra de Sicilia, se conserva un cuaderno de licencias de salida de buques, que abarca del mes de enero al mes de marzo de 1284. En apenas ocho semanas salieron de Mallorca 42 barcos, con el compromiso y fianzas de regresar a la isla en el plazo de tres meses. Esta importante limitación, debido a necesidades estratégicas, tuvo notorias consecuencias. El radio de acción de las embarcaciones no pasó de Sevilla, en el Atlántico, y de Túnez y Sicilia en el Mediterráneo. En estos momentos la composición de la flota mallorquina era: más de $3 / 4$ partes leños, una quinta parte naus y el resto barcas ${ }^{24}$.

Pero ya antes de que terminara la guerra de Sicilia, los mallorquines reanudan sus contactos comerciales con el Mediterráneo Oriental. En 1301, en un pleito de testamentaría, una de las partes llamó a testificar en su favor a tres ciudadanos. El problema era que los tres convocados se encontraban en aquellos momentos en Chipre, como mercaderes ${ }^{25}$. El juez les emplazó a comparecer dentro de seis meses, período que debió considerar suficiente para comunicarles la orden y que pudieran disponer sus cosas para presentarse.

El siglo xIV dispone de una fuente seriada, de control de las salidas de buques de Mallorca, denominada Guiatges, así como una serie de arribadas de buques denominada Ancoratge. Pero ambas fuentes tienen un valor limitado:

- Los Guiatges abarcan desde 1341 a 1460, pero de estos 119 años sólo están documentados de forma completa 54 años y de forma incompleta 5 años (en un total de 9 registros). En cuanto al Ancoratge sólo se dispone de información entre 1321 y 1340 (años 1321, 1324, 1330, 1332 y 1340).

- El Ancoratge era pagado íntegramente por los patrones extranjeros, la mitad de la tasa por los patrones barceloneses y estaban exentos los patrones insulares. Los Guiatges no llevaban aparejada una tasa y perseguían el control de las mercancías exportadas, el lugar de descarga de las mismas y el tiempo de viaje. Se garantizaba su cumplimiento con la exigencia de fianzas ${ }^{26}$.

\footnotetext{
24 A. Riera Melis: Opus cit., pp. 128-139.

25 Se trataba de los ciudadanos de Mallorca Domingo Safont, Bernardo Mogada y Pere de Col de Frares. ARM, AH, S-2, fol. 12 r.

26 Los registros de Ancoratge fueron objeto de un importante trabajo de M. DURLIAT y J. Pons: Recerques sobre el moviment del port de Mallorca ern la primera meitat del segle XIV, en el «VI Congreso de Historia de la Corona de Aragón» (Madrid, 1959), pp. 345-363. Los Guiatges fueron estudiados por F. Sevillano Colom: Historia del puerto de Palma de Mallorca, Palma, Ajuntament de Palma, 1974, pp.185-192.
} 
- La limitación cronológica de estas series, una deficiente elaboración de todos los datos (tipo nave, desplazamiento, origen inicial de la travesía, mención de la carga completa de la nave y albaranes de descarga) hacen que su valor estadístico, para nuestro objeto, sea limitado.

Por ello, en los registros de Ancoratge no figura una sola mención a la procedencia de puertos del Oriente Mediterráneo. Algo mejor son los Guiatges que, complementados con documentación de la época de tipo judicial (especialmente reclamaciones de daños por capturas) nos permiten concluir que durante el siglo XIV constan documentalmente un total de 21 viajes al Levante mediterráneo en circuitos que integran Romania-Chipre, NápolesRomania-Caffa, Romania-Efeso, Creta-Romania, servidos por buques grandes como las cocas, naus de hasta tres cubiertas, incluso alguna galera (de forma un tanto sorprendente un documento de 1336 habla de una galera o saetía) ${ }^{27}$. El leño, el tipo de nave preponderante del tráfico de las islas, apenas era utilizado en los contactos con el Levante mediterráneo.

¿Y Egipto? En 1302 se menciona una nave mallorquina, procedente de Alejandría, que fue capturada por naves chipriotas. Pero el comercio con Egipto, durante el siglo XIV, apenas está representado en las series mencionadas, lo que a veces nos hace dudar si realmente existía o mas bien se trataba de un comercio subterráneo, importante, pero del que apenas se hablaba.

Sólo referencias indirectas, procedentes de fuentes fiscales y notariales nos permiten ponderar el papel fundamental del comercio con Egipto. En 1330 se impusieron tasas sobre todas las embarcaciones según el tipo de nave y su destino. Se trataba de financiar una flota de guerra contra los genoveses. Pues bien las tasas impuestas a los buques que frecuentaban Romania, Chipre, Alejandría y Creta eran las más elevadas junto con las de Flandes e Inglaterra, tal como testifican los datos siguientes:

Tasas comercio con el Levante mediterráneo

\begin{tabular}{lllll}
\hline Área comercial & $\begin{array}{l}\text { Tasa por nau o } \\
\text { coca }\end{array}$ & $\begin{array}{l}\text { Tasa por leño de } \\
\text { bandes }\end{array}$ & $\begin{array}{l}\text { Tasa por leño } \\
\text { grande de una } \\
\text { cubierta }\end{array}$ & $\begin{array}{l}\text { Nau de una } \\
\text { cubierta, galera y } \\
\text { tarida }\end{array}$ \\
\hline $\begin{array}{l}\text { Alejandría, } \\
\begin{array}{l}\text { Romania, Chipre, } \\
\text { Creta }\end{array}\end{array}$ & 15 libras & 4 libras & 7 libras & - \\
\hline
\end{tabular}

27 P. Cateura: Mallorca y Grecia en la baja Edad Media, Atenas, Instituto Cultural "Reina Sofia», 1986, pp. 118-122 y 148-149. 
Los datos anteriores son elocuentes del tipo de nave que servía los viajes a esta región, lo que confirma mis aseveraciones anteriores.

Si las fuentes seriadas de la época no permiten dimensionar estadísticamente el comercio con Alejandría, algunos documentos notariales nos proporcionan un valoración cualitativa. A principios del siglo $\mathrm{XV}$, un mercader joven, Berenguer Sturç, acudió al notario de Mallorca Antoni Contestí, especializado en la contratación comercial. Ante dicho notario manifestó que había cargado 200 jarras de aceite en la nau de los patrones mallorquines Jaume y Bernadó de Tudela, presta a salir rumbo a Alejandría. Hasta aquí el documento era un típico contrato comercial. Pero Berenguer Sturç decidió consignar algunas pinceladas de gran interés. Reconocía que ego, nunquam apud dictas partes Alexandrie hivi, in ipsis partibus non sum praticus, nec assuetus por lo que había decidido ponerse bajo la protección y consejo de Nicolau de Dometo, mercader experimentado, qui pluries in dictis partibus mercantiliter existitis ${ }^{28}$. Lamentablemente las muchas veces que dicho Dometo había estado en Alejandría no aparecen consignadas en ningún documento ${ }^{29}$.

Mejor informados estamos sobre el tráfico comercial del siglo xv. La publicación de fuentes notariales del período $1405-1438{ }^{30}$ y 1448-1480 ${ }^{31}$ nos permite dimensionar el comercio con el Levante mediterráneo, en operaciones donde los mallorquines intervienen realizando comandas comerciales, asegurando mercancías, fletando buques o poniendo sus barcos a disposición de los mercaderes.

El comercio con el Levante mediterráneo (siglo xv)

\begin{tabular}{llllll}
\hline Rodas & $\begin{array}{l}\text { Romania, } \\
\text { Romania- } \\
\text { Rodas }\end{array}$ & Alejandría & $\begin{array}{l}\text { Partes } \\
\text { Orientales }\end{array}$ & Quíos & Chipre \\
\hline 32 & 18 & 17 & 14 & 6 & 2 \\
\hline
\end{tabular}

28 ARM, P-2476 fol. $48 \mathrm{r}$.

29 Los protocolos notariales del mencionado notario, de 1403 y años anteriores, habían desaparecido a raíz de una riada que destruyó una parte de la capital de Mallorca en dicho año.

30 P. MACAIRE: Majorque et le commerce international (1400-1450 environ), Lille, Université de Lille, 1986.

31 O. VAQUER: Navegació i comerç a Mallorca: segle XV, segona meitat, en «Fontes Rerum Balearium», 1, Mallorca, 1990, pp. 95-142. Se trata de un amplio elenco de documentos del notario Bernat Contestí. Del mismo autor: Comerç i capital mercantil a Mallorca (1448-1480) en "La Mediterrània, antropologia i història», VII Jornades d’Estudis Històrics Locals, Palma de Mallorca, Institut d'Estudis Baleàrics, 1990, pp. 161-172. 
En el tráfico respectivo de la primera y segunda mitad del siglo $x \mathrm{~V}$ hay cambios significativos. A partir de 1451 no hay más travesías en dirección a Romania y hay una disminución significativa de los viajes a Alejandría que pasa de 13 en la primera mitad del siglo Xv, a sólo 4 en la segunda mitad del siglo. Los últimos viajes a Chipre y Quíos son del año 1433.

\section{INVERSIONES Y ESTRATEGIAS DE UNA MERCADER DEL SIGLOXV}

Un mercader mallorquín, Huguet Pont, nos revela las estrategias de un negociante insular a mediados del siglo xv. Sus actividades se centran en dos campos: el comercial y el industrial.

Como comerciante sedentario tiene una amplia red de consignatarios y representantes, a menudo interrelacionados por redes de parentesco, en plazas del Magreb (Constantina, Ona y Alcudia), en Barcelona y Valencia, en Rodas - donde vivía su representante Bernat Cotoner-, en Palermo y Gaeta. Además mantiene relaciones comerciales con mercaderes extranjeros como Ambrosio Mechalosa, lombart, Guilem de Cassesaga, Joan Filatzi, florentino, Alexandro Dodo, veneciano, y Bartomeu Asser, de Niza.

Sus actividades son muy diversas (compraventa de especias, aceite, oro y plata, pieles, porcelanas y esclavos), pero sobre todo están focalizadas en la pañería (compraventa de materiales tintóreos, de lana, tejidos) y también en la especulación monetaria (letras de cambio).

Su relación con el norte de Africa es constante y prácticamente siempre sobre las mismas bases de relación: exportación de plata amonedada (en cruats), en barra (en riels) y trabajada (vajillas), de paños de la isla,de especias y de tártaro e importación de oro (grop d'or teber, dobles d'or), cera, dátiles, lana berberesca, grana y nou de xarc.

Con Rodas los intercambios giran en torno a la exportación aceite, lana berberesca y paños y a la importación de algodón, gengibre, canela, pimienta, laca, esclavos. Evidentemente el perfil de las actividades de Huguet testimonia un modo de actuar personal, posiblemente no generalizable, en el que se entremezclan estrategias meramente especulativas (el juego de los cambios monetarios), con las comerciales y de aprovisionamiento de materias primas.

Resulta interesante, al cubrir huecos de la documentación de la época, la cadencia de sus embarques, ya que permiten vislumbrar el tráfico comercial de la época en las secuencias de viaje y tornaviaje. En la tabla siguiente, anotamos las salidas y llegadas a la isla de naves, en cuya carga 
Mundos mediterráneos: el reino de Mallorca y el sultanato mameluco (siglos XII-XV)

Huguet tenía intereses, e incluso en naves llegadas a puertos como Barcelona, con mercancias consignadas a Huguet. No siempre este mercader se muestra escrupuloso en anotar los nombres de los patrones 0 propietarios de buques ni incluso las fechas de embarque o regreso.

Embarque de mercancías del mercader Huguet Pont (1439-1443)

\begin{tabular}{|c|c|c|}
\hline Patrón o propietario & Tipo de nave & Destino \\
\hline \multicolumn{3}{|l|}{1439} \\
\hline- & ballenero & Ona \\
\hline Antoni Gilet & galeota & Contestina \\
\hline Galcerán de Requesens & galera & Alcol-Palma \\
\hline Ramon Desplà & galera & Brujas-Barcelona \\
\hline $\begin{array}{l}\text { Francesc Gilabert de Centelles, } \\
\text { patrón Daniel Pardo }\end{array}$ & galera & Ona \\
\hline $\begin{array}{l}\text { Francesc Gilabert de Centelles, } \\
\text { patrón Daniel Pardo }\end{array}$ & galera & Ona-Palma \\
\hline Antoni Oloerga & ballenero & Ona \\
\hline $\begin{array}{l}\text { Francesc Gilabert de Centelles, } \\
\text { patrón Daniel Pardo }\end{array}$ & galera & Ona-Palma \\
\hline Pere Desplà & galera & Rodas-Palma \\
\hline Nicolau Cantó & galera & Barcelona \\
\hline $\begin{array}{l}\text { Berenguer Bellver, de Ibiza } \\
1440\end{array}$ & ballenero & Contestina \\
\hline Gilabert de Lupià & galera & Ona \\
\hline Galcerán de Requesens & galera & Ona-Palma \\
\hline Gilabert de Lupià & galeota (sic) & Contestina \\
\hline Gilabert de Lupià & galera & Ona-Palma \\
\hline Berenguer Bellver & ballenero & Contestina \\
\hline Melchor Mates & ballenero & Contestina \\
\hline Galcerán de Requesens & galera & Ona \\
\hline Gilabert de Lupià & galeota (sic) & Alcudia \\
\hline \multicolumn{3}{|l|}{1441} \\
\hline Gilabert de Lupià & galera & Alcudia-Palma \\
\hline Falquet & galeota & Norte de Africa \\
\hline Gilabert de Lupià & galera & Alcudia \\
\hline Antoni Castell & galera & Ona-Palma \\
\hline Joan Soler & leño & Barcelona-Paima \\
\hline Francesc Gilabert de Centelles & galera & Contestina \\
\hline Pere Joan de Sant Climent & galera & Rodas \\
\hline Pere Joan de Sant Climent & galera & Rodas-Palma \\
\hline $\begin{array}{l}\text { Joan de Conilleres, patrón Pere } \\
\text { Espanyol }\end{array}$ & galera & Palermo \\
\hline Antoni Castell & galera & Ona y Alcudia \\
\hline \multicolumn{3}{|l|}{1442} \\
\hline Antoni Castell & galera & Ona-Palma \\
\hline Pau Sureda & galera & Ona-Mallorca \\
\hline
\end{tabular}


Embarque de mercancías del mercader Huguet Pont (1439-1443) (Continuación)

\begin{tabular}{|c|c|c|}
\hline Patrón o propietario & Tipo de nave & Destino \\
\hline Pau Sureda & galera & Barcelona \\
\hline Meichor Mates & ballenero & Nápoles \\
\hline Antoni Castell & galera & Ona \\
\hline Tomás Tomás & galera & Nápoles-Palma \\
\hline Antoni Castell & galera & Ona-Palma \\
\hline en Riba & galera & Nápoles-Palma \\
\hline Pau Sureda & galera & Ona-Palma \\
\hline Gilabert de Lupià & galera & Gaeta \\
\hline Melchor Mates & ballenero & Nápoles-Palma \\
\hline M. Sans, de Valencia & nau & Valencia-Palma \\
\hline Antoni Rog & barca & Valencia-Palma \\
\hline Pere Botet & saetía & Contestina-Palma \\
\hline Alexandro Dodo & 4 galeras venecianas & Flandes \\
\hline $\begin{array}{l}\text { Joan de Conilleres, patrón Pere } \\
\text { Espanyol }\end{array}$ & galera & Palermo-Palma \\
\hline Pau Sureda & galera & Ona \\
\hline $\begin{array}{l}\text { Jaume de Galiana y Bartomeu } \\
\text { de Lobera } \\
1443\end{array}$ & dos galeras & Levant \\
\hline Pere Net & $\begin{array}{l}\text { galera, en conserva d'en } \\
\text { Luis Sirvent }{ }^{32}\end{array}$ & Rodas \\
\hline Tomás Tomás & galera & Valencia-Palma \\
\hline Galcerán de Requesens & galera & Nápoles-Palma \\
\hline Melchor Mates & ballenero & Nápoles \\
\hline Tomás Tomás & galera & Alcudia-Palma \\
\hline Gilabert de Lupià & galera & Alcudia-Palma \\
\hline Gilabert de Lupià & galera & Alcudia \\
\hline Pau Sureda & galera & Alcudia-Mallorca \\
\hline en Moncofa & saetía & Barcelona-Mallorca \\
\hline Tomás Tomás & galera & Ona \\
\hline en Taulari & ballenero o nau & Nápoles-Palma \\
\hline Tomás Tomás & galera & Alcudia-Palma \\
\hline Jaume de Galiana & galera & Rodas-Palma \\
\hline
\end{tabular}

La tabla anterior no refleja la intensidad del tráfico comercial, sino las direcciones a las que se dirige la estrategia de un operador como Huguet, aunque éstas no resultan muy alejadas de otros mercaderes isleños ${ }^{33}$. Galeras, galeotas y balleneros se constituyen en las claves del transporte

32 Lluís Sirvent había participado en la embajada, de 1429-1430, que desembocó en el tratado comercial firmado en Rodas, en 1430, entre Alfonso $V$ de Aragón y el sultán de Egipto.

${ }_{33}$ Sobre las actividades proseguidas por sus herederos ver J. RAMIS D'AYREFLOR: Mercaderes mallorquines del siglo XV, en el «Boletín de la Sociedad Arqueológica Luliana» XX (1924-1925), pp. $274,298,315,337$ y 374 ; XXI (1926-1927), pp. 12, 40, 64 y 167. 
marítimo en los viajes de media y larga distancia. En la tabla figuran seis galeras de propiedad isleña (Pere Net, Tomás Tomás, Pau Sureda, Jaume de Galiana, Joan de Conilleres y Antoni Castell) ${ }^{34}$ y otras siete de titularidad foránea ( los catalanes Gilabert de Lupià ${ }^{35}$, Galcerán de Requesens, Nicolau Cantó, Lluis Sirvent, Pere Desplà y el valenciano Francesc Gilabert de Centelles, cuya galera era patroneada por Daniel Pardo).

En el cuadro anterior vemos la cadencia de los viajes a Rodas, que era de uno a dos viajes anuales, siempre utilizando galeras. No es infrecuente en los viajes al Levante el sistema de conserva. Así lo hicieron, en 1441, los patrones Jaume de Galiana y Bartomeu de Lobera y los patrones Pere Net y Lluís Sirvent, en 1443.

\section{CONCLUSIÓN}

En 1240 los habitantes del reino de Mallorca empiezan a comerciar con el Norte de Africa. Siete años después está ya documentado un primer viaje a Alejandría. Desde entonces y hasta el final de la Edad Media los mallorquines no dejarán de frecuentar tanto Egipto, como Chipre y Rodas. Este predominio de las actividades comerciales de los insulares generarán en ellos un espíritu práctico - siempre es mejor un buen negocio que una buena guerra-, tolerante e incluso iconoclasta. Ramon Llull, un filósofo isleño, consagrará toda su vida a encontrar vías de comunicación con los musulmanes, creando en Mallorca una escuela para el aprendizaje de la lengua árabe (1275). Anselm Turmeda optará por convertirse al Islam y ponerse al servicio del sultán de Túnez. Egipto se relaciona con el mercado catalán bien directamente, bien a través de las plazas intermedias de Rodas y Chipre. Es cierto que genoveses y venecianos tienen una posición preeminente en Egipto, pero también el comercio catalán integrará al sultanato mameluco en el circuito de productos altamente cotizados en el Mediterráneo Occidental.

\footnotetext{
34 Por estas mismas fechas sabemos que operaban también las galeras de Jordi de Sant Joan, de Joan Albertí, de Bartomeu Rossinyol y Martí Sagranada y la de los hermanos Pons y Joan Descatlar.

${ }_{35}$ Gilabert de Lupià era hermano del lugarteniente de Mallorca Bernat de Lupià, ejerciente en 1439.
} 